\title{
New Application of High Niobium Cast Iron as a Grain Refiner for Stainless Steels
}

\author{
Hayato Sakaki ${ }^{1}$, Masayuki Mizumoto ${ }^{2}$, Takeshi Ohgai ${ }^{3}$ and Akio Kagawa,a \\ 1 Graduate School, Nagasaki university, Japan \\ 2 Department of Materials Science and Engineering, Iwate University, Japan \\ 3 Department of Materials Science and Engineering, Nagasaki University, \\ 1-14 Bunkyo-machi,Nagasaki 852-8521, Japan \\ a email : akagawa@nagasaki-u.ac.jp
}

Keywords: High niobium cast iron, Grain refinement, Niobium carbide, Stainless steel

\begin{abstract}
In order to develop a new application of cast iron, high niobium cast iron has been developed as a grain refiner for stainless steel. High niobium cast iron was prepared by adding pure niobium to a commercial cast iron. Coarse primary niobium carbide crystals were observed in the microstructure of the cast iron. The effect of the high niobium cast iron on the grain size of austenitic and ferritic stainless steels was examined in various experimental conditions. When the amount of the cast iron inoculant more than 3 mass \% was added into the steel melt, fine equiaxed grains were observed and grain size was significantly reduced to $210 \mu \mathrm{m}$. The results indicate that the high niobium cast iron is effective as a grain refiner for the austenitic and ferritic stainless steels. From the dissolution rate measurement, the grain refining mechanism was proposed.
\end{abstract}

\section{Introduction}

Grain refinement is a well-known strengthening mechanism for metallic materials and the mechanical properties, such as hardness, tensile strength and low cycle fatigue property, are improved by decreasing the grain size of the materials [1-4]. This is a preferable mechanism because it is capable to improve mechanical properties without a change in chemistry and an addition of any harmful elements. Among the grain refinement techniques such as rapid cooling, vibration on solidification, extrusion methods and so on, inoculation method has advantages in cost and energy saving due to its simple processing and no need of high-cost equipments. Recently present authors have reported that the coarse niobium carbide crystals in $\mathrm{Fe}-\mathrm{Nb}-\mathrm{C}$ alloy would act as nuclei on the solidification of nickel base super alloy [2] and austenitic stainless steel [5]. Thus, it is expected that high niobium cast iron would also be a grain refiner for stainless steels. In the present work, the applicability of high niobium cast iron as a grain refiner for austenitic and ferritic stainless steels has been investigated. Furthermore, the solution rate of the inoculants was measured to elucidate the mechanism of grain refinement.

\section{Experimental Procedure}

Cast iron containing niobium and its basic $\mathrm{Fe}-\mathrm{Nb}-\mathrm{C}$ alloys were prepared as inoculants. In the former case, a commercial cast iron(FC200:3.45mass\%C, 2.1mass $\% \mathrm{Si}, 0.7 \mathrm{mass} \% \mathrm{Mn}, 0.20 \mathrm{mass} \% \mathrm{P}$, $0.10 \mathrm{mass} \% \mathrm{~S})$ and pure niobium(99.5 mass\%) were arc-melted under an argon gas atmosphere. In the latter case, $\mathrm{Fe}-\mathrm{C}$ alloys were prepared by melting electrolytic iron and electrode graphite in a high frequency induction furnace under an argon gas atmosphere. Then the $\mathrm{Fe}-\mathrm{C}$ alloys were alloyed with pure niobium by arc melting. In this study, the four types of $\mathrm{Fe}-\mathrm{Nb}-\mathrm{C}$ alloys, i.e., $\mathrm{Fe}-20 \% \mathrm{Nb}-3.0 \% \mathrm{C}$, $\mathrm{Fe}-30 \%-3.0 \% \mathrm{C}, \mathrm{Fe}-20 \% \mathrm{Nb}-1.0 \% \mathrm{C}, \mathrm{Fe}-30 \% \mathrm{Nb}-2.0 \% \mathrm{C}$ was prepared. The alloys prepared were 
crushed into granules and they were sieved to obtain granular additives having a narrow size distribution.

Next, SUS316 stainless steel of $90 \mathrm{~g}$ was melted at $1748 \mathrm{~K}$ in an alumina crucible with an inner diameter of $20 \mathrm{~mm}$. After holding at $1748 \mathrm{~K}$ for $30 \mathrm{~min}$, the alloy melt was cooled to $1723 \mathrm{~K}$ and held for $20 \mathrm{~min}$. Then, the alloy melt was stirred for $5 \mathrm{sec}$ with a silica tube and held for a predetermined time, followed by air cooling. The microstructure of the specimen was observed on the transverse sections with an optical microscope and a scanning electron microscope. In addition, in order to examine the availability of the inoculant in an industrial scale, the dissolution rate of additives was measured using the apparatus shown in Fig.1, where an apparent weight loss was monitored as a function of time.

\section{Results and Discussion}

\section{Modification of Inoculant Composition}

In the earlier work [2], one of the authors have developed a new inoculant based on $\mathrm{Ni}-\mathrm{Nb}-\mathrm{C}$ ternary system for the grain refinement of Nickel base superalloys. The inoculant contains a primary $\mathrm{NbC}$ in the matrix consisting of $\gamma \mathrm{Ni}+\mathrm{NbC}$ eutectic and a coarse $\mathrm{NbC}$ was considered to act as a nucleus for primary $\gamma \mathrm{Ni}$. When the $\mathrm{Ni}-\mathrm{NbC}$ inoculant was added into SUS304 austenitic stainless steel melt at $1723 \mathrm{~K}$, a coarse columnar grain structure was observed and no grain refining effect was detected on the horizontal section of a $20 \mathrm{~mm} \phi$ round bar sample. However, an equiaxed fine grain structure was found at the bottom on the vertical section of the casting as shown in Fig.2.

This is due to a density difference between SUS 304 steel melt $\left(7870 \mathrm{~kg} / \mathrm{m}^{3}\right)$ and the nickel base inoculant $\left(8670 \mathrm{~kg} / \mathrm{m}^{3}\right)$. Thus, the nickel should be replaced by iron in an inoculant for iron base alloys.

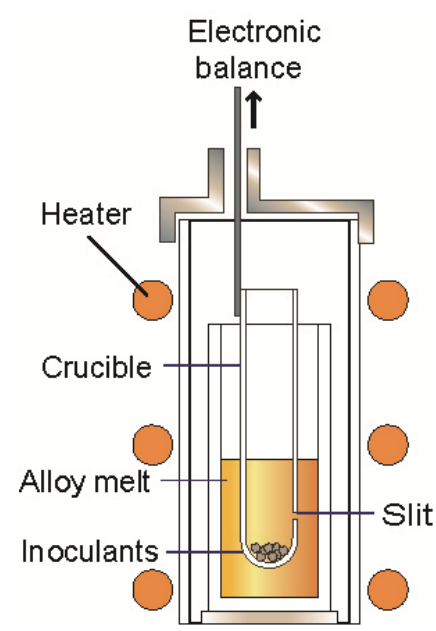

Fig.1. Schematic of the apparatus for dissolution rate measurement.

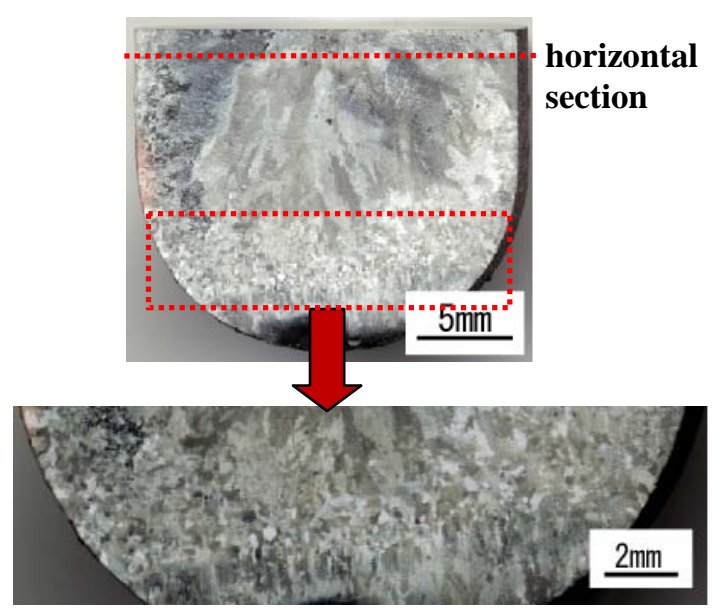

Fig.2 Macrostructures of SUS304 stainless steel after inoculation treatment with Ni-Ni-C alloy additive.
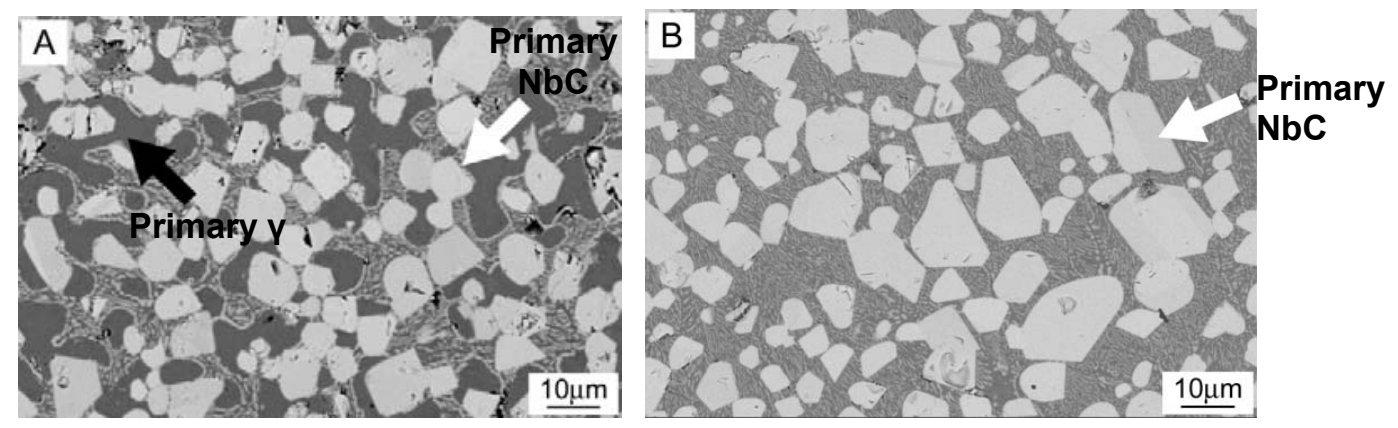

Fig. 3 Microstructures of high niobium cast irons prepared from different starting materials. A: synthetic cast iron, B: high niobium cast iron. 


\section{Microstructure of Fe-Nb-C Alloy and High Nb Cast Iron Inoculants}

Figure 3 shows the microstructures of niobium containing cast irons prepared from different starting materials; A: Fe -30 mass $\% \mathrm{Nb}-2.45$ mass $\% \mathrm{C}$ (pure iron+electrolytic graphite + niobium), $\mathrm{B}$ : $\mathrm{Fe}-30 \mathrm{mass} \% \mathrm{Nb}-2.45 \mathrm{mass} \% \mathrm{C}-1.4 \mathrm{mass} \% \mathrm{Si}-0.5 \mathrm{mass} \% \mathrm{Mn}-0.14 \mathrm{mass} \% \mathrm{P}-0.07 \mathrm{mass} \% \mathrm{~S}$ (cast iron FC200+niobium). Coarse primary NbC crystals were observed in the both microstructures. According to the $\mathrm{Fe}-\mathrm{Nb}-\mathrm{C}$ phase diagram [6], the matrix structure consists of $\gamma+\mathrm{NbC}$ eutectic.

\section{Effect of Holding Time on Grain Size}

To investigate the effect of holding time on the grain size, molten SUS316 steel was held for various periods after the addition of niobium cast iron of 3 mass $\%$ with an average granule size of $0.5 \sim 1 \mathrm{~mm}$. Macrostructures of the specimens for different holding time are shown in Fig. 4. In the case of without holding after stirring for $5 \mathrm{sec}$, fine equiaxed grains were observed (Fig. 4 (a)) and the grain size was about $210 \mu \mathrm{m}$, while in the case of the holding time of $30 \mathrm{sec}$, coarse columnar structures were observed (Figs. 4 (b)) and the effect of additives seems to disappear. It is suggested that high $\mathrm{Nb}$ cast iron inoculant with
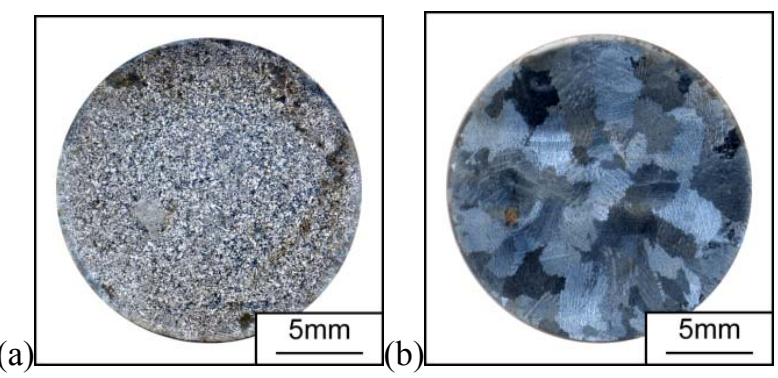

Fig. 4 Effect of holding time on the macrostructure of SUS316 steel. (Inoculant : $30 \mathrm{mass} \% \mathrm{Nb}$ cast iron with $0.5 \sim 1 \mathrm{~mm}$ in granule size)

(a) stirring for $5 \mathrm{sec}$ and held for $0 \mathrm{sec}$,

(b) stirring for $5 \mathrm{sec}$ and held for $30 \mathrm{sec}$. a granule size of $0.5 \sim 1.0 \mathrm{~mm}$ has a high dissolution rate in the melt of SUS 316 steel.

\section{Effect of Granular Size and Inoculation Temperature on Grain Size}

The influence of the granular size of inoculant on the macrostructures of SUS430 steel is shown in Fig.5. When the inoculation temperature is $1783 \mathrm{~K}$, the inoculant with a coarse granule size of $3.0 \mathrm{~mm}$ displays grain refining effect, while at $1753 \mathrm{~K}$, fine grain structures were observed on the addition of inoculant granules grater than $1.0 \sim 1.5 \mathrm{~mm}$ and the effect was maintained up to $45 \mathrm{sec}$. This indicates that coarse granules have a relatively low dissolution rate into the melt.
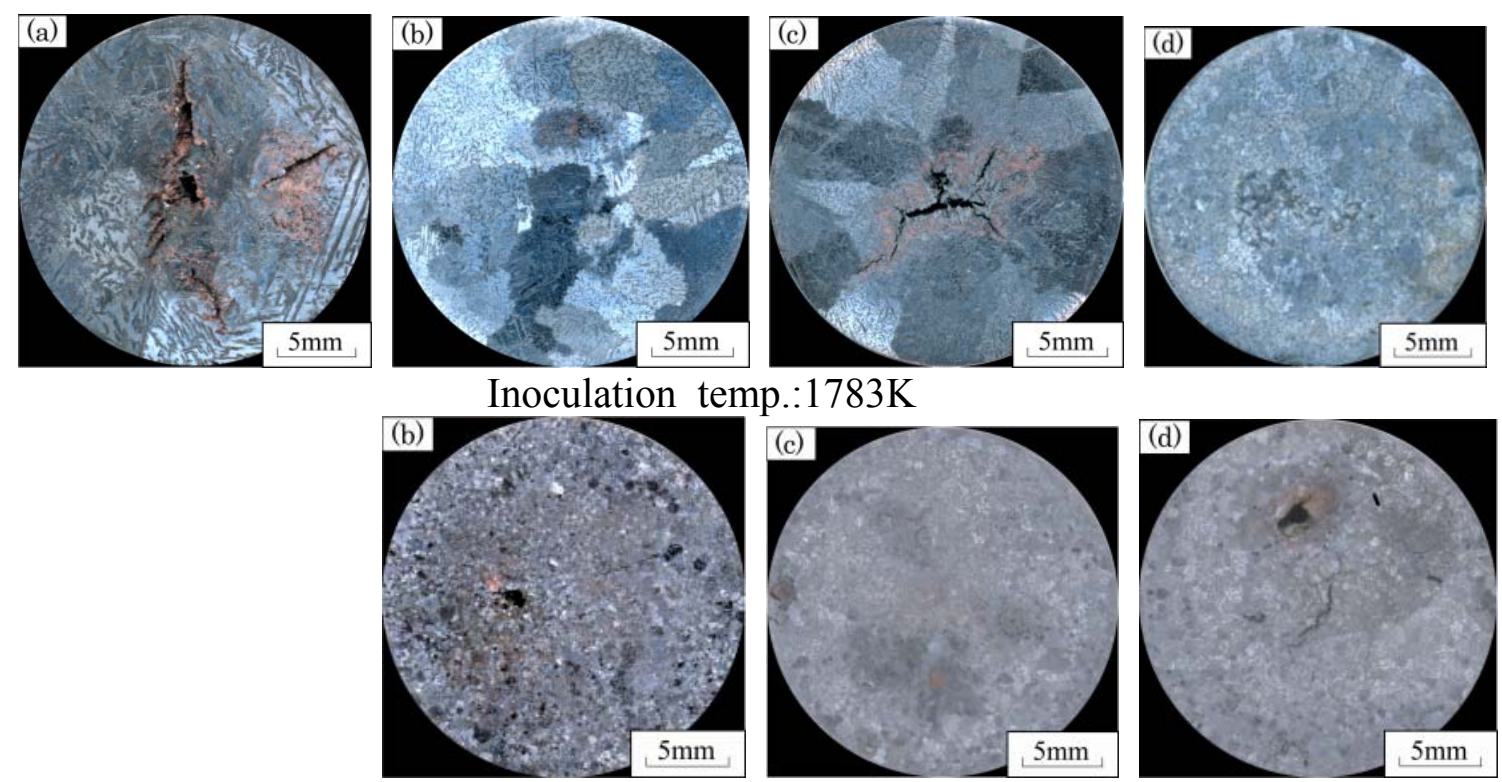

Inoculation temp.:1753K

Fig. 5 Influence of the granular size of inoculant on the macrostructures of SUS430 steel.

(a) no inoculation, (b) granular size $1.0 \sim 1.5 \mathrm{~mm}$, (c) granular size $2.0 \mathrm{~mm}$, (d) granular size $3.0 \mathrm{~mm}$. 


\section{Effect of Area Fraction of Primary NbC on Grain Size}

Typical microstructures of two inoculants (a:Fe-20mass $\%$ $\mathrm{Nb}-1$ mass $\% \mathrm{C}$, b:Fe-30mass $\% \mathrm{Nb}-2$ mass $\% \mathrm{C}$ ) are shown in Fig. 6. The matrix structure is a mixture of two eutectics, $\gamma+\mathrm{NbC}$ and $\gamma+\mathrm{Fe}_{2} \mathrm{Nb}$ for the former and $\gamma+\mathrm{NbC}$ for the latter, respectively. The area fraction of primary $\mathrm{NbC}$ crystals in the inoculants measured by image analysis was $8.3 \%$ and $38.2 \%$, respectively. The average grain sizes of SUS316 stainless steel subjected to the inoculation treatment using these inoculants under the condition of the granule size of $0.5 \sim 1$ $\mathrm{mm}$ and the holding time of $0 \mathrm{sec}$ were about $1000 \mu \mathrm{m}$ and about $200 \mu \mathrm{m}$, respectively. This indicates that the primary $\mathrm{NbC}$ could act as nuclei. TEM observation near the undissolved primary $\mathrm{NbC}$ crystal and primary $\gamma$ in a sample having a fine equiaxed grain structure revealed a formation of a semi-coherent interface between $\mathrm{NbC} / \gamma$. The detail of the interface relationship will be given elsewhere [7].

\section{Mechanical Properties of Fine Grained Stainless steels}

Figure 7 shows $0.2 \%$ proof stress of SUS 430 stainless steel having a fine equiaxed grain structure, together with that of a coarse grain structure sample. The proof stress is given as an average for more than three tensile specimens. The sample having a fine grain structure shows a higher proof stress by about $10 \%$ in comparison with a sample without the inoculation treatment.

\section{Dissolution Rate of Inoculant}

Weight loss of two typical inoculants (in Fig.6) is shown in Fig.8. After the addition of the inoculants into the SUS316 stainless steel melt at $1738 \mathrm{~K}$, weight loss was measured using the apparatus given in Fig.1. The weight loss curves consists of two regions. 1) a rapid wight loss region from the start (s) to the time (p), 2) a gentle weight loss region after it. Since the matrix consists of eutectics

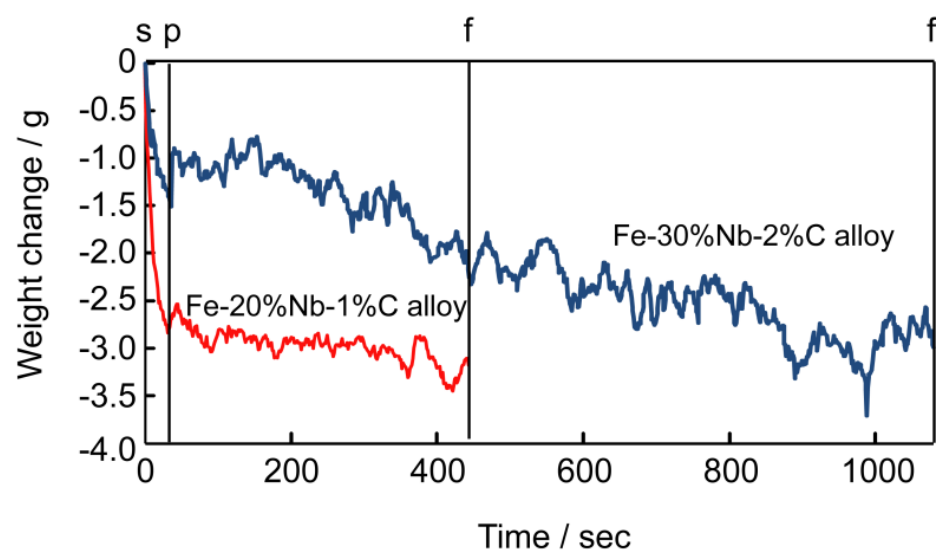

Fig. 8 Influence on the rate of solution by the difference in composition in additives.
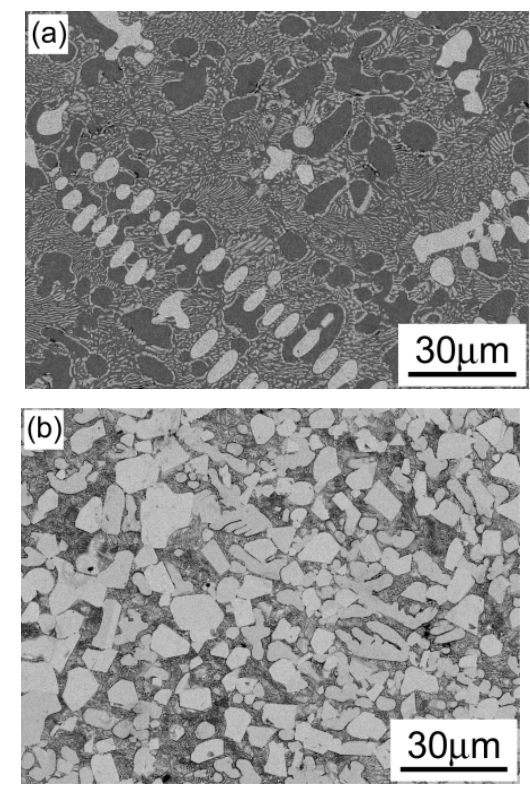

Fig. 6 Microstructures of inoculants having a different area fraction of primary $\mathrm{NbC}$.

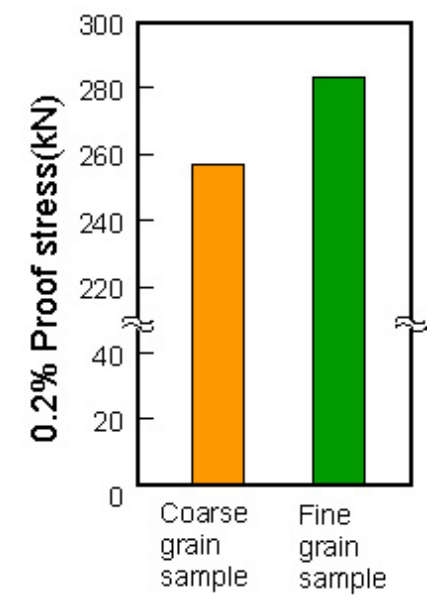

Fig. $70.2 \%$ proof stress of SUS430 steel having a fine equiaxed grain structure.

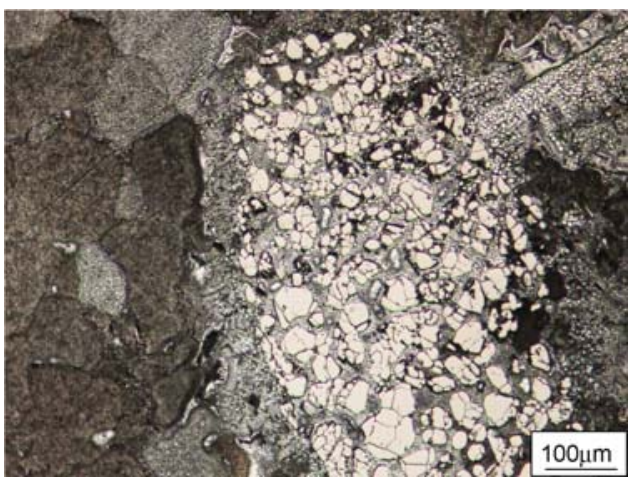

Fig. 9 Microstructure of a fragmented granule of the inoculant. 
having low melting points, it is considered that the rapid weight loss indicates melting of the matrix and the gentle one corresponds to melting of the primary $\mathrm{NbC}$. Change in weight loss ceased at different time (f) which seems to depend on the amount of primary $\mathrm{NbC}$ in the inoculants. Figure 9 shows a microstructure of a fragmented inoculant granule in the quenched sample after addition of the inoculant. This suggests that such a fragmentation of the granules may occur due to thermal stress at early stage of the inoculation treatment.

\section{Mechanism of Grain Refinement}

From the inoculation experiments under various conditions, it is known that the grain structures of austenitic and ferritic stainless steels depend on 1) size of granules, 2) area fraction of $\mathrm{NbC}$ in the inoculant, 3) holding temperature and 4) holding time. These suggest that primary NbC crystals act as nuclei of primary $\gamma$ on the crystallization of these steels and wherether fine grain structures can be obtained or not depends on the dissolution rate of the inoculant, i.e. those of matrix and primary $\mathrm{NbC}$. Schematic illustration of grain refinement mechanism is shown in Fig. 10, which consists of the following steps.

1. Coarse inoculant is added into the melt

2. The inoculant granules are fragmented into fine granules

3. Fragmented fine granules are dispersed into the casting.

4. undissolved primary $\mathrm{NbC}$ acts as nuclei for primaly $\gamma$, resulting in fine equiaxed grain structure.

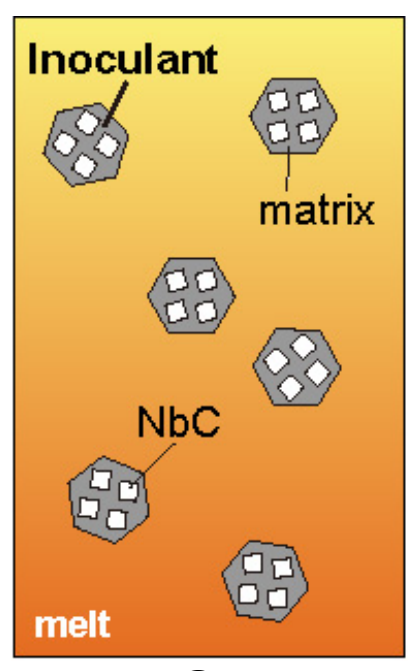

(1)

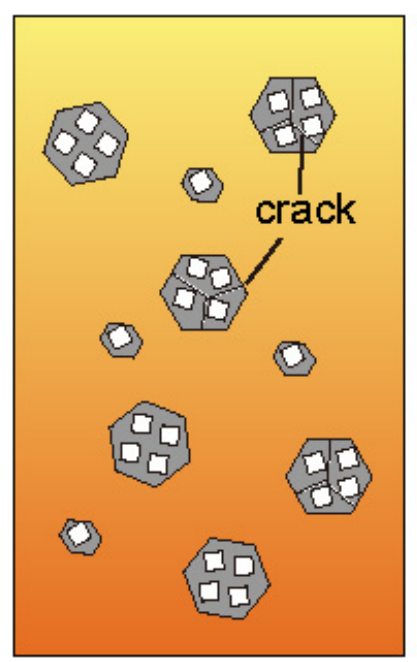

(2)

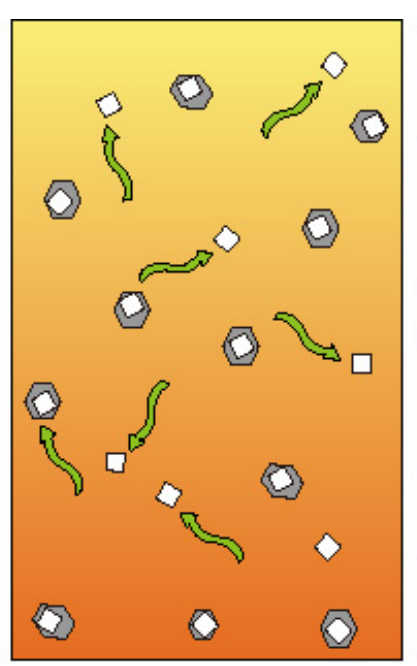

(3)

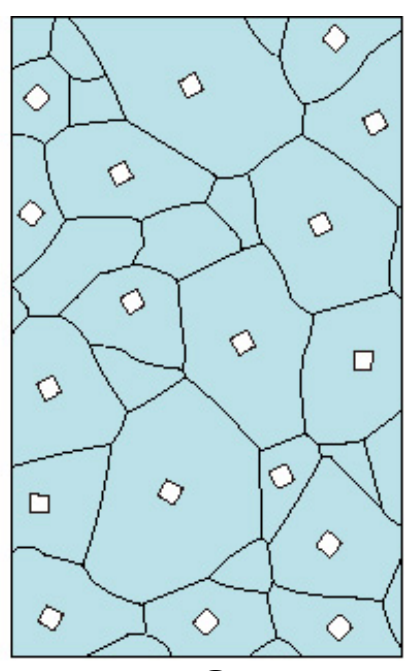

(4)

Fig. 10 Schematic illustration of grain refinement mechanism. 


\section{Conclusions}

The applicability of high niobium cast iron as a grain refiner for austenitic and ferritic stainless steels has been investigated and the mechanism of grain refinement was elucidated from the measurement of the dissolution rate of the inoculants. The results obtained are given as follows.

(1) The area fraction of primary $\mathrm{NbC}$ crystals in $\mathrm{Fe}-\mathrm{Nb}-\mathrm{C}$ alloy additives tends to increase with increasing both $\mathrm{Nb}$ and $\mathrm{C}$ concentrations of the inoculant.

(2) When the amount of inoculant more than 3 mass $\%$ was added into the steel melt, fine equiaxed grains were observed and grain size was significantly reduced to $210 \mu \mathrm{m}$.

(3) Optimum conditions for the grain refinement of SUS316 are as follows: the inoculation temperature $1726 \mathrm{~K}$, the stirring time $5 \mathrm{sec}$, the holding time $0 \mathrm{sec}$ for the granule size of $0.5 \sim 1 \mathrm{~mm}$ and $0 \sim 45 \mathrm{sec}$ for the granule size of $1 \sim 1.5 \mathrm{~mm}$.

(4) When the area fraction of primary NbC crystals in the inoculant was lower than $10 \%$, the effect of grain refining was not significant, indicating that coarse primary $\mathrm{NbC}$ crystals acts as nuclei of primary yof austenitic and ferritic stainless steels.

(5) The grain refinement mechanism is considered to consist of four steps, i.e., 1) Coarse inoculant is added into the melt. 2) The inoculant granules are fragmented into fine granules. 3) Fragmented fine granules are dispersed into the casting. 4) undissolved primary $\mathrm{NbC}$ acts as nuclei for primaly $\gamma$ resulting in fine equiaxed grain structure.

(6) It is elucidated that a high niobium cast iron has a new function as a grain refiner for stainless steels.

\section{References}

[1] C.N.Wei, H.Y.Bor, C.Y.Ma and T.S.Lee: Mater. Chem. Phys. Vol.80(2003), p.89

[2] M. Mizumoto, S. Nomura and A. Kagawa:Trans. Indian Inst. Met. Vol.58 (2005), p. 597

[3] L.Liu, T.Huang, Y.Xiong, A.Yang, Z.Zhao, R.Zhang and J.Li: Mater. Sci. Eng. Vol.394 (2005), p.1

[4] W.Jin, F.Bai, T.Li and G.Yin: Mater.Lett. Vol62 (2007), p.1585.

[5] M. Mizumoto, S. Sasaki, T. Ohgai and A. Kagawa: International Journal of Cast Metals Research Vol. 21 (2008), p. 49

[6] H.Ohtani, M.Hasebe and T.Nishizawa: CALPHAD Vol.13 (1989), p.183.

[7] M. Mizumoto, S. Sasaki, T. Ohgai and A. Kagawa: submitted to Journal of Materials Research (2010) 